\title{
Designing Documentary Informatics
}

\author{
Chris Elsden ${ }^{1}$, Abigail C. Durrant ${ }^{2}$, David Chatting ${ }^{1}$, David S. Kirk ${ }^{2}$ \\ Open Lab, Newcastle University ${ }^{1}$ \\ Newcastle-upon-Tyne, UK \\ \{c.r.elsden; david.chatting\}@ncl.ac.uk \\ Northumbria University $^{2}$ \\ Newcastle-upon-Tyne, UK \\ \{abigail.durrant; david.kirk\}@northumbria.ac.uk
}

\begin{abstract}
In this paper we describe a Research through Design inquiry about a speculative wedding documentation service, in the mode of the Quantified Self. We reflect on our design research, which included design ethnography, interviews, enactments of parts of the service, and the production of a concept brochure. In so doing, we explore the design of personal tracking as a documentary activity, one intended for longer-term self-expression and remembering - rather than simply to monitor, regulate and motivate a data-driven life. Developing the Lived Informatics discourse, we use our design-led inquiry to propose 'Documentary Informatics' as an alternative and longer-term design perspective on self-tracking tools.
\end{abstract}

\section{Author Keywords}

Documentary Informatics; Data-Driven Life; Quantified Self; Speculative Methods; Remembering; Weddings;

\section{ACM Classification Keywords}

H.5.m. Information interfaces and presentation

\section{INTRODUCTION}

As a 'data-driven life' [55] is increasingly possible, researchers in Human Computer Interaction (HCI) have, of late, looked beyond 'extreme users' [8] to consider the lived and socio-cultural experience of quantified lifestyles $[18,19,29,38,50,53]$. Rooksby et al. set out the foundations for this experiential perspective as 'Lived Informatics' [45], and critique 'technology-centric' stage-based models of personal informatics [34] that prioritize behavior change. Adopting a phenomenological perspective, Lived Informatics [45] describes the diverse styles and idiographic meanings that emerge from the interweaving of selftracking and quantified data in people's everyday lives.

Our work in this paper is concerned with one particular 'style' reported by Rooksby et al. - 'documentary tracking'. In this style, participants "were interested in documenting their activities rather than changing them." [pp. 1167, 43]

Figures1, 3-7: CChris Elsden. Figure 2: CChris Elsden, David Green.

Permission to make digital or hard copies of all or part of this work for personal or classroom use is granted without fee provided that copies are not made or distributed for profit or commercial advantage and that copies bear this notice and the full citation on the first page. Copyrights for components of this work owned by others than ACM must be honored. Abstracting with credit is permitted. To copy otherwise, or republish, to post on servers or to redistribute to lists, requires prior specific permission and/or a fee. Request permissions from Permissions@acm.org.

DIS 2017, June 10-14, 2017, Edinburgh, United Kingdom (C) 2017 ACM. ISBN 978-1-4503-4922-2/17/06 ...\$15.00

DOI: http://dx.doi.org/10.1145/3064663.3064714
Despite focusing on behavior change, Li et al. [34] also report documentary uses of quantified data to reminisce or to manage their affairs. In our own prior work (herein Elsden et al. [17]), we interviewed long-term trackers about their 'quantified past', as an emerging personal record.

Rooksby et al. emphasize that most tracking, documentary or otherwise, is a prospective and promissory activity, focused on the very recent past, present and near-future [45] - few participants in their study showed interest in longterm documentary tracking. Elsden et al. also note that only half of their participants had deliberately looked back on their historical data [17]. One interpretation we posit here is the extraordinary extent to which the current research and design of data-driven tools is focused on present and shortterm goals - simply becoming 'fitter, happier, and more productive' [19]. Perhaps then, it is unsurprising that selftracking is approached as a present-focused activity.

Viewed only through stage-based models of behavior change (e.g. [21,34]), data risks being viewed as simplistic, and one-dimensional. However, the quantified data that can now be collected on the body, in the home, in places of work and on the street, is often much more descriptive. Put another way, 10,000 steps is never just 10,000 steps. It is also a commute, a hike, or sightseeing in a foreign city. Lived Informatics hints at this broader relationship with data, which is derived from and unavoidably tangled up in diverse aspects of our everyday lives. Elsden et al. contend that whatever the initial motivation for self-tracking - the instrumental use for data at the time - this data has the potential to document people's lives over time [17].

Taking these observations as our departure point, this paper asks: 'what would it mean to prioritize these documentary uses of data, in the design of personal informatics tools? How might we reconfigure the design of data-driven services for longer-term self-expression and remembering, rather than only to monitor, regulate and motivate?'

This paper presents a Research through Design (RtD) $[25,57]$ project, which turns to speculative methods to frame and address these questions. The basis of our project was to speculate about the design of a 'wedding datagraphy' service (as a parallel to wedding photography) to professionally capture and curate meaningful and evocative data from a wedding. Though unique events, weddings provide an intriguing documentary context in which data might support experiences of sharing and remembering one's wedding, rather than optimizing it. 
To investigate this speculation, the project pursued multiple strands of design-led inquiry. This initially involved: design ethnography; the use of design workbooks; interviews; and the design and deployment of promotional materials. These strands culminated in two 'speculative enactments' [14] in which two engaged couples met a wedding 'datagrapher' to discuss data they could document about their wedding. Both couples were then featured in a 'real wedding' style article describing their experience of wedding datagraphy. We designed, laid out and professionally printed these articles as a fictional brochure, promoting Abacus, our proposed wedding datagraphy service. In this paper, we critically reflect on the process and multiple outcomes of these design-led engagements with research participants.

By working in a speculative context prioritizing long-term self-expression and remembering, we propose that our exploration of wedding datagraphy contributes a foundation for the design of a new class of personal tracking tools: 'Documentary Informatics'. We suggest that coining this new class of tool takes seriously the documentary potential of quantified data, with opportunities for alternative and longer-term uses of personal tracking.

\section{RELATED WORK}

\section{Documenting Everyday Life with Quantified Data}

Rooksby et al. [45] describe documentary tracking in terms of a personal interest to document activities rather than change them, and the authors offer several examples. They suggest that some people document "out of interest"; for example, nurses who wonder how far they walk in their working day. Documentary tracking is frequently pursued out of more than just curiosity, and is used to "underline effort" or commitment. Others are reportedly tracking "to work out information about their routine activities"; for example gaining a sense of their average speeds cycling to work (ibid. pp. 1167). These practices resonate with Lazar et al.'s [33] described use of trackers for "curiosity"; once a satisfactory answer has been found, continued tracking is no longer necessary. Lastly, Rooksby et al. [45] describe how participants use trackers "to document pleasurable experiences, and couples using trackers on special walks", (ibid. pp1167). Such tracking enhances the activity at the time, but appears to be valued in the longer term as well. In all these cases, people are appropriating trackers to use them in a documentary way, often as a means to tell stories about themselves, usually in the here and now.

However, Kim et al. [32] note that even after tracking has finished or stagnated, many people sought to keep or control access to their data. Lazar et al. [33] report on those who continued tracking, hoping for future potential use of their data, even when it was no longer useful for them. Indeed, "this expectation for future benefit led participants to stop using devices that did not store data” (pp. 641).

Anticipating this future use and reflection on data as a quantified past, Elsden et al. [16,17] report examples of the ways in which self-tracking data could be valued for documenting one's past. Participants reflecting on longterm data remarked on changes and transitions in their lives. Places they used to live and commute from; recovery from injuries; leaving university. Participants could easily recount different periods of their life - intense busyness, moving home, or dieting. The tracked data prompted reminiscence about these times, as well as specific events, such as a music festival or winning a triathlon. Equally, however, data could sometimes appear anonymous, or routine, and by itself, of limited documentary interest.

These studies suggest that users of personal tracking devices are aware of the potential value - or at least the implications of - the long-term storage of data that documents their daily activities. As such, while much documentary tracking reported by Rooksby et al. is largely focused on the present time; it appears that quantified data can have documentary potential beyond its original capture. As a supplementary point, it is important to recognize the communicative and social role of documentary tracking. Rooksby et al. [45] emphasize how their study was suffuse with the telling and reflection of "something akin to a life story" (pp. 1171). Elsden et al. position their inquiry [17] alongside recent work on digital possessions [40] and technology heirlooms [3,39], which emphasizes a sociocultural perspective on remembering [4,36]. From this perspective, remembering is a reconstructive and collective achievement; memory is a 'resource-for-action', rather than simply 'something-in-the-head' [30].

Through this related work, we are building a position that documentary tracking is not simply a way of creating copies or impressions of reality, but is also a means of communicating personal narrative, identity and a felt sense of self (selfhood). Elsden et al. suggest that 'objective' quantified data is made personally meaningful through contextualization or 'data work' [17]. Davis [9] suggests: "narratives and subjective interpretations are the mechanisms by which data morphs into selves". Verisimilar accounts of everyday life emerge from the interweaving and appropriation of data with personal accounts.

\section{Quantified Data as Identity, Narrative and Selfhood}

Useful parallels can be drawn between data and practices and orientations towards photography. Van House et al. describe the daily communicative uses of photographs [52]. Miller and Edwards emphasize a transition from telling stories about photographs, to telling stories with photographs [37], as a form of social communication $[10,47]$. Equally, we could consider more communicative and social uses of data, something a variety of researchers, designers and artists have begun to explore as a way of "seeing ourselves" [43].

Epstein et al. [20] describe the challenges and some of the awkwardness of sharing data on social media as impression management. However, Sharon [49] paints a particularly nuanced portrait of self-trackers in the Quantified Self 
movement, who, more than simply data-fetishists, have complex relationships with their data, using it to enact a kind of authenticity. "Rather than a numerical and constraining understanding of the self, as critics decry, this may point to an open-ended aesthetic one, where identity is constructed and curated, the product of quantitative and qualitative piecings together" [p23, 33]

The self as a product of these 'piecings together' was the subject of our recent Metadating project [18]. Singles were invited to create a 'data profile' about themselves, and use this to talk about themselves at a speed dating event. Crucially, this work emphasized how talking about and 'performing' one's data was distinct from analyzing it, with implications for the style, presentation and detail required.

The work of artists and designers pushes the boundaries of data as a documentary material. Graphic designer Nicholas Felton has produced ten annual 'Feltron reports' [24], which detail many aspects of his life in data, from daily activities, to personal communication and media consumption. At the time, they were an exercise in selfawareness and annual reflection. They are now remarkable documents of his life. Stefanie Posavec and Giorgia Lupi also focus on everyday phenomena (e.g. their wardrobes, thankyous, swearwords and greetings), by exchanging 52 weekly self-portraits of hand-drawn data postcards for a year [42]. Lastly, Mimi Onohua's "data storytelling project" Pathways [41] presents interactive stories about four families based on passively collected mobile messaging and geo-location data. These are brief, but instructive, examples that emphasize the documentary potential of quantified data and the way that it can become imbued with a sense of personal identity and humanity.

\section{Towards Documentary Informatics}

These social and performative uses of data are integral to Lived Informatics, and suggest the potential for a less goaloriented relationship with quantified data. Herein we contend that much of this relationship turns on the inevitably descriptive and documentary nature of a datadriven life. The related work captured here suggests that new kinds of documentary are an inevitable by-product of a data-driven life, which can support identity construction and narrative expression with quantified data. Nonetheless, despite identifying this documentary potential of a datadriven life, very little work in HCI has explicitly considered the design of what we term Documentary Informatics.

\section{WEDDING DATAGRAPHY AS A DESIGN-LED INQUIRY}

We have described how the driving paradigm of a Quantified Self is short-term, goal oriented, focused on selfoptimization and behavior change, rather than documentary. Speculative RtD approaches (e.g. [5,13]) have been appropriated by HCI as a way to critique and explore 'alternative presents' [1] and near futures, which break from such existing paradigms of technology use. Hence, we turned to speculation to configure a design space that shifts potential values of personal informatics towards long-term self-expression and remembering; specifically, services for recording one's wedding with quantified data. This was used to foster empirical engagement around possible documentary interactions with data in a possible social reality that we constructed for both our research team and our research participants to explore. In such a context, our participants, and we as researchers, could have tangible, performative and real-life engagements with the proposition of long-term documentary tracking. In this way, we pursued a design-led inquiry: that is, an HCI study that is led by creative design practice. A combination of RtD methods were brought to the design of a number of linked empirical studies. We now describe these studies, in chronological order of how they were conducted. In practice, the studies were overlapping and mutually informing.

\section{The Wedding Datagraphy Concept}

The concept of wedding datagraphy - to professionally produce evocative data from a wedding - emerged from an ideation exercise undertaken with colleagues to develop design briefs for services to support remembering with data. We understood a wedding to be a particularly significant life event, where great importance is placed on personal expression and shared remembering through the careful recording and documenting of the day. In a rich description of existing technology use at weddings, Massimi et al. [35] highlight how photographs, video and treasured mementos are used to reassert the 'magic' of the day. Most importantly, we felt that weddings would be far removed from more goal-oriented notions of behaviour change, and would support an explicit focus on documentary styles of tracking. Although weddings are exceptional, rather than everyday events, they provide a context that many people can evocatively and excitedly relate to. As an initial exploration of the potential of documentary informatics, we sought to play with this prosaic cultural setting.

\section{Design Ethnography}

Our inquiry began with Design Ethnography [46], through which we sought opportunities to document quantified data about a wedding. We referred to wedding magazines extensively, visited a wedding fair, and clipped online material from popular wedding blogs and wedding vendors' websites. Initial clippings were photocopied and annotated, or gathered in the Evernote tool. We were particularly attentive to idealized wedding aesthetics, diverse modes of documentation, and the rhetoric, process and representation of wedding photographers. We produced three design workbooks [27] to elaborate and share initial ideas and concepts from this ethnographic work. These became a frequent source of reference, and directly fed into a number of the subsequent design activities. An initial output was the design of a brand for our datagraphy service: 'Abacus'.

\section{Abacus Data Cards}

Through our design ethnography, we considered different approaches and structures to the overall conceptual service design. We focused mainly on examples of documentary data, setting aside any immediate technical or practical 
barriers to the data collection. Examples were identified as prose statements (e.g. 28 steps down the aisle; Your guests travelled 2,374km; 13:01 - Your first kiss). We attended to the form of the data, and the language used to present it. From this study we realized the need to develop a playful, flexible way to introduce the wedding datagraphy concept to others (e.g. research participants or potential clients). To this end, we developed a deck of 52 Abacus Data Cards [Fig. 1], which rapidly communicated the breadth of quantified data forms we were interested in. These were partly inspired by the wealth of existing card-based ideation tools [e.g., 21]. These cards became our go-to method for introducing and explaining the service.

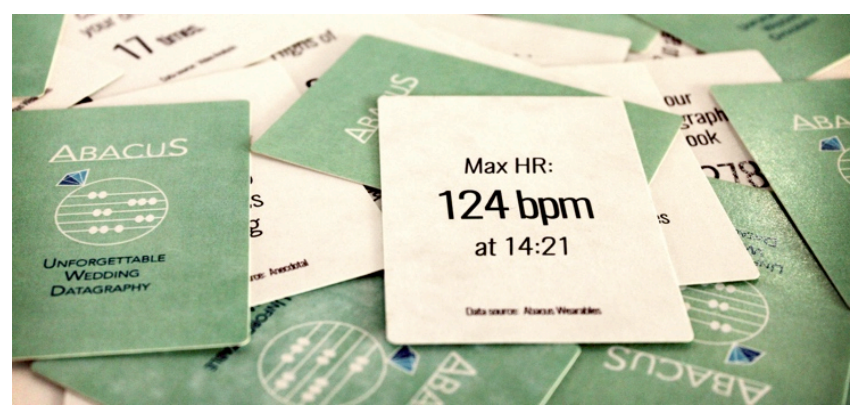

Figure 1: Abacus Data Cards.

\section{Interviews}

We conducted 12 semi-structured interviews (P1-P12, 7M, $5 \mathrm{~F})$. This was a convenience sample, including two wedding photographers, eight recently married individuals, one married couple, and one engaged individual. At interview, we invited participants to describe their own wedding. We probed in particular about their efforts to document the day, and their use of photographs, video, mementos and social media. We asked the photographers to describe their role and practice on the day, seeking opportunities to ground the role of the datagrapher.

In the second half of each interview, we gave participants a pack of Abacus Data Cards and asked them to pick out data that they would have found compelling to record about their wedding. As a twist, we asked them to choose five cards for themselves, and five cards for their partner, and any cards they found inappropriate. Their choices scaffolded a broad conversation about the kind of data that could be captured from a wedding, and its personal, historical value. These interviews extended initial insights from our design ethnography, and in particular insights into actual practices of wedding documentary, particularly around photos. The interviews, augmented by the cards, allowed us to pilot a way of speaking about the speculative service in a plausible and appealing manner.

\section{Speculative Enactments}

Rather than deploying the proposed wedding service in full, we focused on developing one feature of it in-depth, as a Speculative Enactment. Speculative Enactments are an RtD approach proposed by Elsden et al. [14,15], to design consequential and social circumstances in which participants are invited to act amidst and experience speculation. Speculative Enactments hence invite empirical analysis as part of a speculative design-led inquiry.

For an enactment of the quantified wedding service we envisioned, we were drawn to the meetings that engaged couples have with their photographer to discuss and plan their wedding photography. At this stage of planning, couples are already excitedly imagining, disagreeing on and deciding how to document their big day. We sought to connect with these kinds of interactions in the context of our speculative datagraphy service.

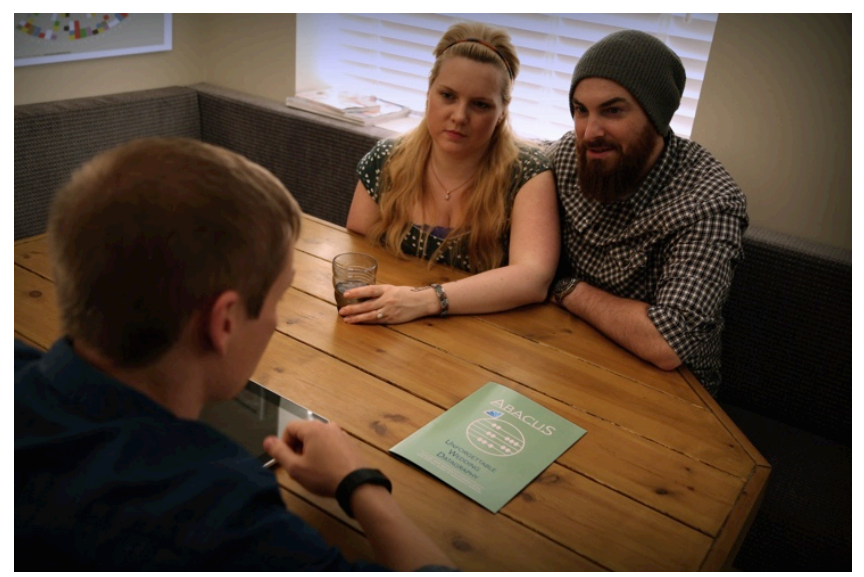

Figure 2: Promotional image of 'meeting a datagrapher'.

We created and staged a competition for two engaged couples to meet with an Abacus datagrapher. We did this through the design of an Abacus website, advertised through social media and local wedding vendors:

Come and imagine the future of wedding recording with us. We are seeking TWO engaged couples, to feature in a concept brochure for Abacus. We want to imagine and tell the story of your future wedding, as it would be captured with data. Our chosen couples will meet exclusively with an Abacus Datagrapher to discuss their wedding, and how they would capture and represent it with data.Our datagrapher will then produce a four-page feature article on your imagined wedding, featuring data and mementos from the day. They will share this with you for a final edit, before publishing in a 12-page concept magazine about wedding datagraphy.

We hoped to attract imaginative couples who would enjoy speculating on the possibilities of the service. We were not intending to deploy a datagrapher at their wedding - we felt this was technically and ethically beyond what we could achieve. Instead, we proposed writing a 'real-wedding' article about them: as a tangible outcome; intended as a valued memento for the couple; and as promotional material for the concept. We recruited two Scottish couples. Annabelle \& Calum were to be married in Edinburgh just two months after our meeting. Annabelle would arrive at her wedding in a big red bus that would later take guests on 
a tour of the city. Rowan \& Julia were to have a 'rustic and relaxed' wedding the following summer (eight months later) in the grounds of stately home in Yorkshire, with tepees and a hog roast.

Each couple was sent the Abacus Data Cards as a Cultural Probe [26]. As before, they were invited to choose cards for themselves and for their partner, but keep this secret until our meeting. The lead author, in the role of a wedding datagrapher/researcher, visited each couple twice at their homes. Both meetings were audio-recorded. The first of these discussed their upcoming wedding, and then their choice of data cards, which served as a kind of data catalogue. This scaffolded an open-ended conversation about the meaning and value of different kinds of data.

We responded to this initial conversation and drafted a 500word article imagining the couple's experience of wedding datagraphy. This incorporated a large portrait photo, and images of three fictional 'data artifacts', imagined to be produced after their wedding. The draft article was sent to the couple in advance, and the second meeting focused on editing and discussing it. These conversations allowed the couples to identify and represent themselves through the data, and speculate about its prospective use - both as an imagined artifact and as the actual brochure to be published. In this respect, couples were engaged both in speculation about the service, but more immediately in impression management, with the datagrapher and through the article. Finally, both couples were posted the published wedding brochure [Fig. 7], delivered inside 'Rock \& Roll Bride', a popular UK wedding magazine.

\section{Data Artifacts}

Images of the data artifacts formed the centerpiece of the articles. These were a bespoke design response, part of a dialogue between the couple and their datagrapher. They were proposed as mementos to represent their data, which we wanted the couples to see as reflecting them and their wedding. These artifacts were portrayed in print, through the brochure. There were three for each couple, who refined the data they displayed at the second meeting.

\section{Annabelle \& Calum}

For Annabelle and Calum, their central artifact was an infographic printed onto the side of a big red bus [Fig. 3]. This included mainly aggregate data, such as the number of wedding guests, a graph of dance floor activity, and the total bar spend. (Remarkably, Annabelle still had a hotel receipt from her parents' 1971 wedding). In discussion with the datagrapher, the couple envisaged the bus as a large print to be displayed in their living room. They even asked for the original image so that they could rework it after their wedding with data they anticipated they could capture, a request demonstrating the depth of the couple's engagement with the artifact and the scope of a Datagraphy service.

A second data artifact was a set of coasters [Fig. 4], overlaid with the path of the couple's first dance, as well as turns and holds. Annabelle and Calum warmed to the coasters as playful and ambiguous. They imagined them as a conversation starter, around which tales could be spun.

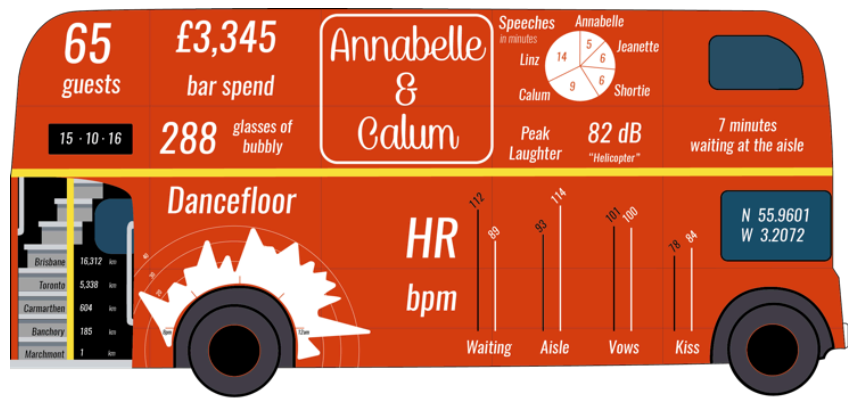

Figure 3: Annabelle \& Rowan's bus infographic.
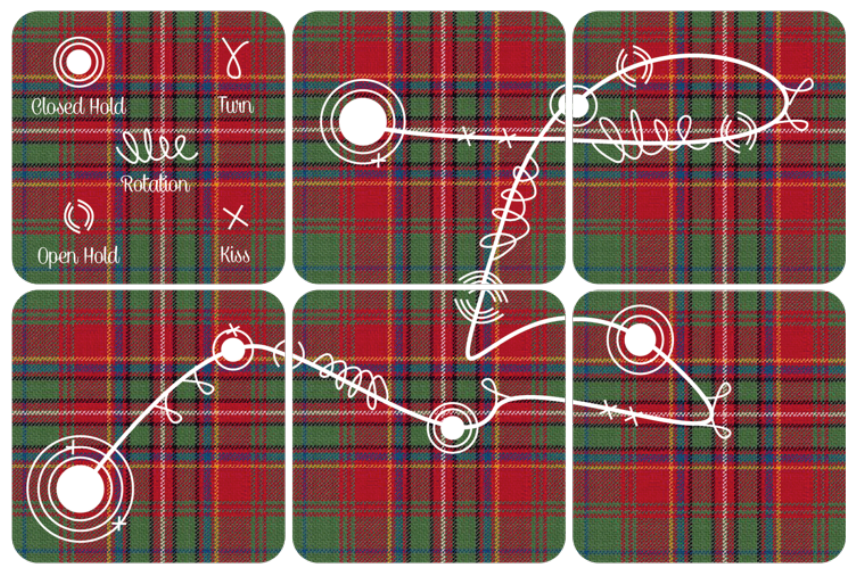

Figure 4: Coasters decorated with the pattern of a first dance.

Lastly, they were presented with a playing card declaring the precise time of their first kiss. The couple had actually included decorative playing cards in their invitations to their guests. During the enactment, the couple felt the exact time would become a ritual on their anniversary, as they would playfully recreate the moment. In design terms, it is notable how simple and memorable this data point is, it does not require elaborate representation. Like one's time of birth perhaps, this would be something that was simply known and remembered, rather than necessarily on display.

\section{Julia \& Rowan}

Julia and Rowan envisaged a timeline of their day, not only of traditionally important events, but also amusing, unique or infelicitous moments that could index their character and the 'style' of the day [Fig. 5]. In many of our interviews, participants were curious about, and extraordinarily grateful for, the travel of their guests. Julia and Rowan imagined an interactive map that would (like a video) play out the trickle of guests arriving to their venue. As many guests knew each other, the couple anticipated this being of interest to their guests as well as to themselves.

Julia's sister is a florist, so the flower arrangements for their outdoor reception would be a significant and shared part of the event. The couple felt this could somehow be captured 
with data. Rowan and Julia imagined data about the quantity and variety of the flowers being bound up with photos of the flowers themselves [Fig. 6], perhaps in an album together. Felton's examples of 'photoviz' [23] illustrate the potential of this visual mixing of photographic images and data. Within the scope of this paper, we offer brief, bespoke examples that are limited to what we may represent in print. These illustrate the possible opportunities for valuable representations of documentary wedding data.
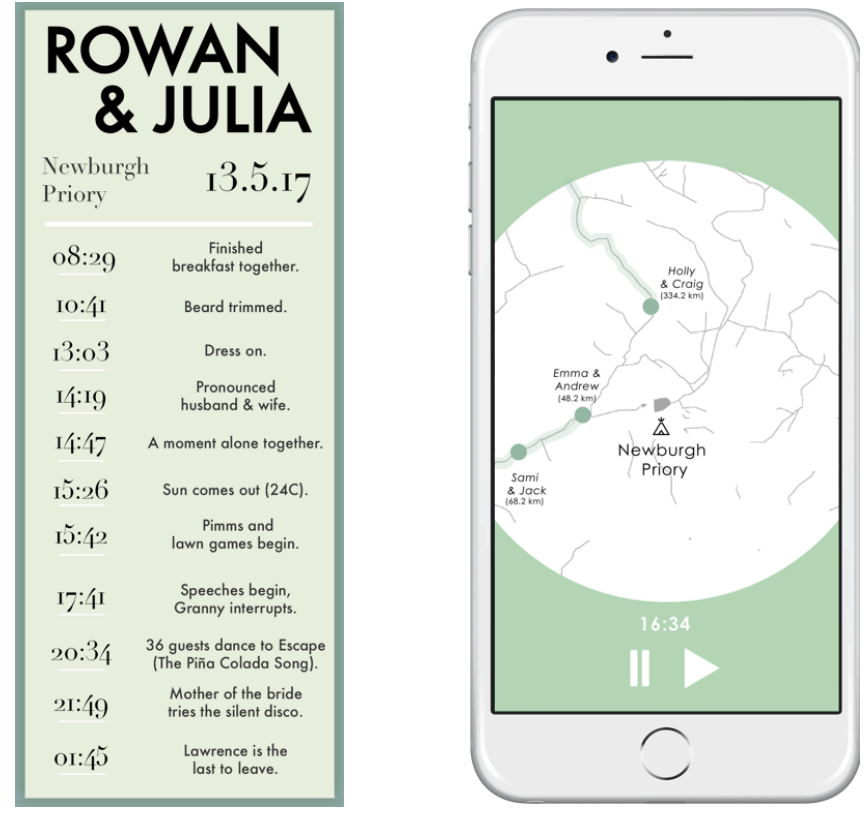

Figure 5: For Julia \& Rowan, an alternative timeline of the day, and an interactive map of the arrival of their guests.

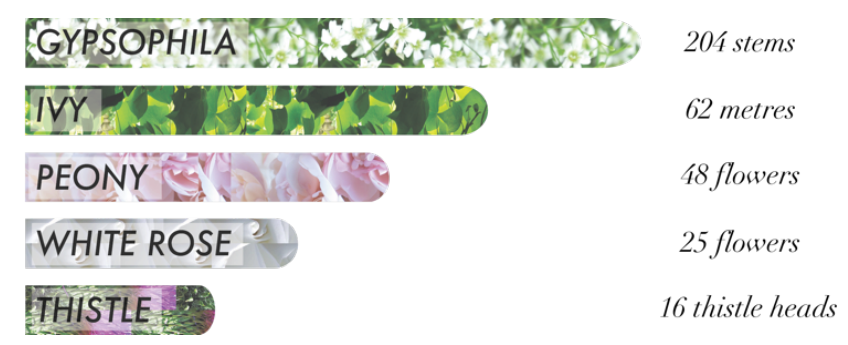

Figure 6: An infographic of the flowers at their wedding.

\section{Brochure}

The final 16-page, B5 brochure [Fig. 7] consists of: a front and back cover; an introduction to the Abacus service; and two 'real-wedding' stories. Its design mimics pullouts commonly found inside magazines, and is printed on glossy paper. The introduction gives a broad suggestion of a service in three parts; 'Collection; Processing; and Curation'. A datagrapher supports couples in deciding what data they could collect, capture and process, presenting numerous options for representing and sharing this data.

The immediate role of the brochure was as a boundary object, between the datagrapher and participating couple, as well as to give some consequential outcome to the enactment. Ultimately, the brochure functions as a Design Fiction artifact [5]; it communicates a possible world in which Annabelle \& Calum, and Julia \& Rowan, were married with Abacus Datagraphy. It is important to note that the couples were not anonymized in the design research process - the brochure would be for them to keep, and perhaps reflect on, later. They were aware that the brochure would be published and used to promote future articulations of the concept, at wedding fairs or even in the media.

\section{Analysis}

The many outcomes from these activities - i.e. design workbooks, interviews, cards, brochures, enactments, design artifacts - are each available to many analytic lenses. Within the scope of this paper, we perform a higher-level analysis, reflecting both on our engagement with the speculation, as designers and reflective practitioners [48], as well as our participants' responses to it. Practically, we have reflected on many field notes, our design workbooks, and interviews, as well as the resulting design artifacts - the Abacus Data Cards, the data artifacts, and the brochure.

In pursuing 'Lived Informatics' [45] our perspective is phenomenological and experience-centered [56]; we attempt to convey the felt experience of documentary tracking, and the way this speculation became interwoven with people's lives. We first describe our understanding of the central values and motivations in documenting a wedding with data, drawn primarily from interviews and enactments with the Abacus Data Cards. Secondly, we reflect on the design of the Abacus service and data artifacts to elicit design considerations for documentary tracking.

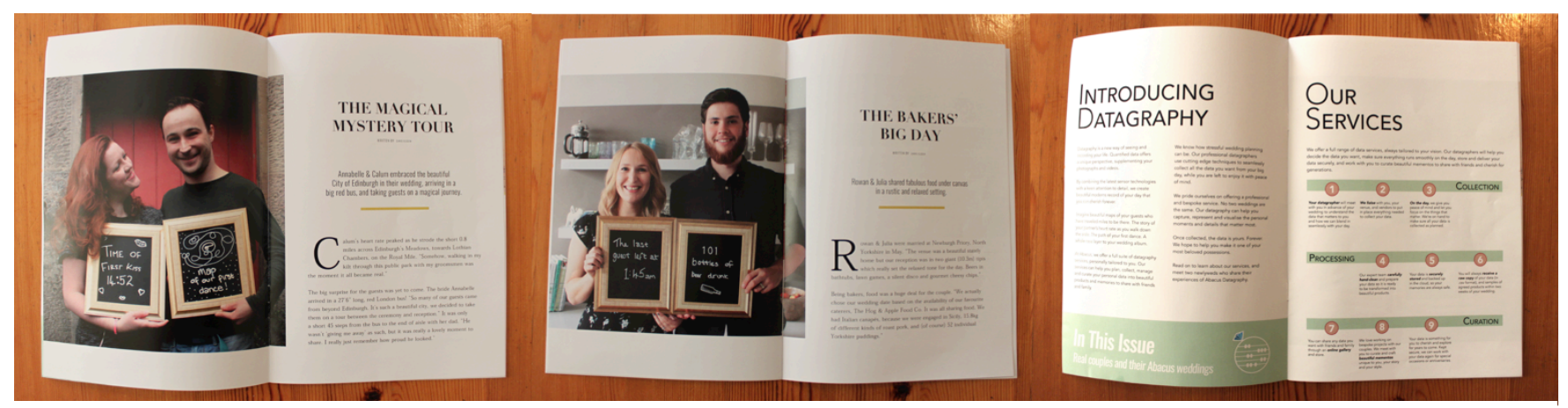

Figure 7: The wedding brochure. (Left to right) Annabelle and Calum; Julia and Rowan; an introduction to Abacus' services. 


\section{WHY DOCUMENT A WEDDING WITH DATA}

Through early interviews, and especially the enactments, our participants presented a range of values for documenting their wedding with data. In general terms, our interview participants painted a picture of their wedding as a wonderful but overwhelming experience. Those already married described how the event flew by so quickly; it took a long time to appreciate and make sense of the day. Over time, memories of the day settled into a series of anecdotes about key moments, and photographs were framed or collated in albums. There are desires to relive parts of the day, but this unfolds slowly, in the months and years following the wedding, with friends and family.

In these accounts, data was variously approached as a means to gain some purchase on the bewildering day: to create a new perspective; to highlight particular events; to acknowledge the event as a set of achievements; to show people having fun celebrating. Throughout, participants engaged with the prospect of documentary data quite playfully. Data did not seem to carry the same 'weight' as official or formal posed photographs might. This was not "scientific collection" but often more "anecdotal funny" data (P12). This lightness was perhaps a reaction to data that might be too determinative, jarring with the 'magic' [35], which people seek to reconstruct after the event.

But while much data would be something "fun to know" at the time, it was not always anticipated as something to really remember. Numbers can matter immensely in the successful planning of the day, but quickly fade from view. Data that might be valued longer term tended to do what we might call 'wedding work' for a couple, in three main ways. 1) It represented their experience; 2) It represented the wedding itself; 3) It played a social role. Clearly, photos, videos and mementos are the main outlet for this work. But these illustrate ways in which participants were able to transpose the values and experiences of wedding documentary onto quantified data.

\section{Representing their personal experience as a couple}

Participants often personally related to data that had a particular likeness to their own experiences, or invited them to tell specific stories from their day. 'Nine minutes alone together' rang true for several individuals. Participants weren't clear that they would explicitly set out to record such data, but on reflection, it was evocative when it aptly defined a felt experience. "The heels thing's hilarious because I took mine off instantly after I got out of the ceremony." [P3] Relatedly, participants identified data that expressed their personal touches. "19:29, the 12 minute cigar' stood out to one participant, for whom cigars were " $a$ big thing" [P3] in her groom's family. In this case, the data itself is perhaps less significant than the topic of cigars. The data is used to signify that cigars are something that matter, and are worthy of record. Annabelle \& Calum's bus is a 'data portrait' [12] that signifies and calls out all of their interests. "We love the bus, big time. Like an image of that for us to keep would be great." For well travelled couples, a map of where their guests had arrived from was almost universally appealing. Such a map in itself says much about the couples' own identity and geography.

\section{Representing the wedding day}

Data could be reflective of a wedding's thematic styling; Julia and Rowan felt their timeline reflected the rustic and relaxed feel they hoped for their wedding. Other data highlighted distinctive or highly personalized parts of the day, which often had become part of the telling. For a couple married on a cold February day, the weather, and temperature were significant. "It's something that we remember about the day, that it was really cold, but it was a really nice day. It'd be just quite nice to have some figures associated with that... it shaped quite a few things" [P8]. Seeking to capture data about a first kiss, or steps down the aisle was often simply another way of marking the importance of these moments, rather than an intense curiosity about whether one walked 28 or 32 steps.

Data can have an aggregating quality, providing totals and summaries. In documenting a wedding, this was imagined to show the achievement of the wedding day itself. The extent of guests' travel, the total number of glasses of champagne, the numerous handshakes, the time everyone finally went to bed: these all speak of that unique 'piecing together' [49] of things and the collective efforts of many people to make the wedding happen.

\section{Social roles of data}

Many sought data that would become a "talking point". Heart rate might playfully reveal who was the most nervous or excited. Rowan imagined telling his future children "Do you know how long your mum took to get ready? I was left waiting for 45 minutes!". Records, such as the bar bill, or the longest confetti line [P3] were anticipated as details to be raised with friends. Others sought to use data to recognize significant roles that others played in the day such as time spent with bridesmaids [P1], creating flower settings together [Julia], or making a playlist [P5].

Sharing wedding data was conceived in the same way as sharing wedding photos. For example, some considered incorporating data "as a really nice thing to put in thank you letters" [P1]. However, there was awareness of data that could be contentious or sensitive, particularly relating to the expense of a wedding, or revealing of family politics.

\section{DESIGN REFLECTIONS}

Though it is important to underline the potential motivations for documenting a wedding with data in the first place, our focus in this paper is primarily on the design of services and technologies to support this.

\section{Documentary data as a resource for action}

Harper et al. [30] describe memory-as-a-resource-foraction. In line with the socio-cultural study of memory, this perspective emphasizes that remembering is not simply the recall, or record of events (as suggested by lifelogging). 
Instead, remembering entails the inevitably social and cultural ways in which the past is incorporated, and brought to bear on the present [30,36]. As a parallel, Frohlich et al. [47] suggest, "photos operate not as copies of reality but as statements people can make about themselves".

Our point is that the purpose of documenting a wedding is not to obtain a complete, unerring record of the day, but as a resource for particular kinds of remembering. Everything that is captured - video, photos and mementos are inevitably, and subjectively, edited down, and very often stored away. Photographers do not promise clients 'the most accurate record of your wedding', nor do they produce 'evidence'. Many see their documentary photography as an art - producing just one possible representation of the day. One photographer we spoke to described his role as "taking the whole wedding, and breaking it down into small little moments, which together make the entire wedding" [P2]. Another prioritized taking "one killer image" [P11].

Indeed, some couples eschew too much documentation, lest it diminish the experience as remembered or disturb their own "holistic memory" [P1]. The choices couples face about which photographer to hire, for how long, whether or not to also record video, or to record the speeches, and so on - are oriented towards accomplishing remembering that couples anticipate being important for them. Our effort through this inquiry has been to explore the qualities of data as a documentary medium in order to consider how our participants, and our own design work, could appropriate data as a new resource with which to do 'wedding work'.

\section{Designing poetic data}

Quantified data connotes scientific precision and objectivity. Yet, it is clear that a precise record is rarely a valued a way of remembering a wedding. For weddings in particular, people tend to want to remember the magic, and not necessarily all the details [35]. Further, there is a contrast between naturally reconstructive human remembering [4] and the kind of certainty offered by datadriven descriptions of the world [11]. This presents a fundamental design challenge for data as a personal documentary medium. In wedding datagraphy, it has meant playing with what one participant called "a poetic response" [P1]. This is not only to romantically propose data as art: rather, to highlight the way data can succinctly distil some essence of the experience. Masses of data could be constructed as 'true', but evoke almost nothing of the experience, hence meaning little in this context.

Cartier-Bresson, French master of candid photography, describes his search for the "decisive moment" to take a photograph, which recognized "the significance of an event as well as of a precise organization of forms which give that event its proper expression."[6]. The wedding datagrapher is not then a scientist or a technician: just as the job of a wedding photographer and a police photographer are utterly different. Part of the datagrapher's presumed skill is being able to capture and present data that "give that event its proper expression". Massimi et al. emphasize the recording of "special moments of spectacle that act as indices into the event" [33]. The forms of data chosen for Annabelle and Rowan's bus seek to do this. Like a collage, we imagine a new detail drawing attention at each glance.

In our inquiry, we have been more concerned with the experience of remembering than with its precise recall with those memories that bring joy, comfort, or a shared sense of identity, even if the details might become hazy, or change over time. Hence representations of data that seem to aptly sum up a couple, or that chime with visceral experience-as-remembered, became more valuable than even data that gives a more 'accurate' picture of the day.

\section{Data as an alternative lens}

As we have described, weddings are momentous events. They make for overwhelming personal experiences. Part of the role of documenting a wedding is to grapple with, and to at least partially pin down, defining experiences from it. Datagraphy offered further hooks into remembering, understanding, and reconstructing experience. On occasion, we found data could express context or details - e.g. distance, heart rate, playlists - that other media lacked. Like the effort of guest's travels: "photographs, it doesn't capture that at all" [P6]. But more often, data provided another focus on significant details already captured by photo or video - the exact moment of marriage, the colors of the day, or one's steps down the aisle. In this way, data acted as an alternative lens that was valued because it might offer another viewpoint on particular special moments. Presentationally, data was frequently imagined alongside photographs - either as context, or as an artifact or index that would encourage seeking out other mementos.

This is an approach to documentary recognizing that a complete representation of the entire wedding is inevitably beyond reach. The experience is always unfinalized, and is continually open to being made sense of by others, from a multitude of perspectives that may change over time [2, 56]. The playfulness of the events represented on Rowan \& Julia's timeline suggests an alternative to the official schedule, or expected milestones of the day. We became aware of avoiding data that has a totalizing effect or presenting things as unequivocally so. One participant rejected the idea of an exact transcript of his speech, but imagined keywords or word counts as a more ambiguous alternative, open to interpretation: “...enough that if you were there it would be a prompt, a reminder of that story but it didn't give away the details" [P12].

\section{Data, Photos and Video}

In the course of our speculation, datagraphy was rarely presented or interpreted as competing with other media. Of course in practice, in terms of a couple's budget, space and time on the day, this may not be so. Nonetheless, a lot of attention in this project concerned the differing qualities of video, photo and data as documentary media. 
Video appears to divide opinion, with many couples not stretching to the expense, or only recording specific parts of the day, such as the ceremony or the speeches. Video requires performance [44] and dedicated attention to sit down and watch it. One photographer described video as "impressive - it impresses emotion on to you" [P11]. By contrast, he suggested photography was more extractive, and candid photography allowed people to remember being in a particular moment. A number of others reflected this sentiment - that photographs, especially candid ones, could "stretch a moment out" [P2], and generated an imaginative space around them, which invited reflection.

Our instinct was to imagine data that worked in a similar extractive way. From a poetic standpoint, data can be remarkably compact and pointed, inviting opportunities to imaginatively contextualize around the data. This resonates with findings from the Metadating event [18] emphasizing the discursive value of ambiguity around data. Presenting only the time of a first kiss invites remembering of that moment, and for Annabelle and Rowan, subsequent ritual on their anniversary. Data could expansively be used to document every moment of the couples whereabouts on the day - but we would suggest this is not its documentary power. Instead it can deeply and succinctly cut through to particular aspects of the experience which mediate valued remembering. As the datagrapher, we sought data that provoked imagination, ahead of providing explanation.

\section{Designing for social remembering}

Remembering weddings is particularly collective. These are not just personal experiences. While the couple is the centre of attention, many people share and participate in the documentation and remembering of the day. Yet, as personal informatics, Elsden et al. [17] note that data can appear particularly ego-centric. A challenge of wedding datagraphy was to make data sociable.

We found interest in producing representations of data, such as the coasters of a first dance: left at hand and easily encountered, drifting in and out of attention. These were available as "talking points" for guests in the home. In this way, the ambiguity of Annabelle \& Calum's 'first dance' coasters, supported a social curiosity. Aggregate data, to which all the guests had contributed, or within which they could identify themselves also appealed. A photographer described making a 'wedding wall'. He photographed every guest individually against a wall, and then stitched the individual images together to create a large print showing every guest at the wedding. Reportedly guests try and find themselves in the picture, appreciating their place at the wedding. We considered how Rowan \& Julia's interactive guest map might have a similar inviting effect.

\section{Curating Documentary Data}

Within the Quantified Self movement, it is widely acknowledged that the challenge is no longer just gathering 'enough' data; it is about being able to make sense of it. This goes beyond simply making the data digestible. In the wedding context, curation concerned marking things out as worthy of recording in the first place; such choices already invest meaning and expectation in the data.

Media curation takes place throughout: in the decisions made beforehand about what to record (perhaps by the datagrapher on the day); and subsequently in the choice of means to represent the data. Perhaps most interestingly, the project raises questions about who plays this curatorial role. A photographer is usually trusted to take, and curate the best few hundred photos, but as Julia suggests: "Our photographer is just going to give us loads of photos... Because I would choose the ones I want myself." Arguably, people are much more literate in the use and curation of photos than data. So what then are the boundaries for curation and authorship of data? If the couple were to have the raw data, what form would this take? A dashboard? A CSV file or spreadsheet?

\section{Summary}

We have located the roots of our speculative inquiry in Rooskby et al.'s 'documentary style' of personal tracking, and the use of quantified data towards remembering and self-expression. Though weddings are a special case for documentary, they are nonetheless a prosaic concern, broadly experienced and relatable, providing a crucible for us to explore the potential of Documentary Informatics. Further work should certainly explore the degree to which the documentary practices of a wedding might translate to the documentary of 'day-to-day' life connoted as 'Lived Informatics'. Still, we suggest that these Design Reflections are foundational for a new documentary approach to the design of data-driven tools that prioritize documenting one's activities rather than changing them.

\section{OPPORTUNITIES FOR DOCUMENTARY INFORMATICS}

Below, we suggest a series of opportunities and challenges, in an effort to advance the design and research of Documentary Informatics tools.

\section{Snapshot Datagraphy}

Support the crafting of spontaneous 'snapshots' with data, as distinct from documenting pre-conceived activities.

Through the design of the Abacus service, and particularly the enactments, it became apparent that preparing to capture data about the wedding event often required anticipating things that would happen. Couples told us that cigars were important, or that they were interested in the activity on the dance floor. Practically, these would need to be attentively set up for measurement or observation.

Akin to Cartier-Bresson [6], the roving candid wedding photographer is attentive to key moments, but also able to pivot, and capture events as they unfold. These impromptu moments - like grandad playing with his grandson - are often some of the most valued. In contrast, the datagrapher seems constrained. Whereas photos can be conceived of, and taken in an instant, data capture seems to occur over a much longer period of time. 
Leading from this, can we imagine new ways in which one might take spontaneous 'snapshots' with data? What tools might a datagrapher carry on the day? Wilkens [54] designed a 'weather camera' device for example. Fundamentally, we imagine these might be tools to rapidly count with; ways of making categories; means of following movement, perhaps. Nicholas Felton's app 'Reporter' [22] offers a highly customizable reporting interface to regularly quantify things people care about, in self-defined terms. What might a more real-time, in the moment, approach to such applications offer? Data analytics and graphics company Chryon Hego employ analysts to capture live data from sports events using Xbox controllers [7]. The latest GoPro wearable cameras now overlay telemetry data in real-time [28]. This sort of functionality, channeled through a smartphone app, could create intriguing new possibilities for 'snapshot' datagraphy.

\section{Providing new orientations to traditional media Data could significantly shape alternative orientations to photography.}

Another way to read our design efforts here would be as an exploration into whether or not quantified data could take on some of the documentary qualities of photography. We do see a lot of value in this inquiry, but the dominant role of photography as a technology of memory [51] is clear. A fitting role for data could be in supporting different orientations to photography, and possibly video as well. The use of 'smart journal' applications, combining multiple media and data streams already hints at this possibility [16].

In the first instance, this requires ways of linking representations of data to media - for example, Rowan imagined the interactive guest map as an alternative platform for guests' photos. While there may always be a traditional chronological narrative to one's photo album or wedding video, documentary informatics could provide a non-linear mapping through vast media records.

\section{Physicalizing as curating a fixed form}

Giving data a fixed form forces active curation and meaning making.

The nature of designing a printed brochure with our engaged couples saw the curation of data mainly by giving it physical form. This also fitted with expectations of printing and framing wedding photos, and displaying mementos in the home. On reflection, we find that the physical nature of the bus infographic, the timeline, and the coasters created a fixed form for data. Committing to these physical forms contrasts with digital representations of data, which are highly malleable, and subject to frequent transformations and inter-connection. As a design opportunity, we suggest committing to a more fixed form enhances the long-term value of the representation. Not only is the data at hand, developing a sense of possession; but by making choices about their data's embodiment, couples invested it with meaning and personality. Data can then settle in place [50] as part of the rituals and anecdotes, which develop in the couple's practices of remembering their wedding. Documentary informatics tools might encourage these sort of curatorial and framing exercises.

\section{New editorial roles}

Data can require extensive editing and curation, opening up new editorial roles.

One trend from our inquiry has been our participants' preferences for certain specifics and particulars around which remembering could be oriented. As such, the data that could document a wedding requires extensive editing and curation. The Abacus service suggests that a datagrapher takes on much of this work. Photographers and videographers agree broad instructions, but are then trusted to capture and edit the highlights of the day as they choose. Our participants were quite directly involved in deciding the data that would be captured and represented. As a service, we imagined differing degrees of engagement, from bespoke design with couples, to pre-selected package products. Documentary Informatics should address the nature of these editorial roles, whether automated in places, or divided between individuals and services.

\section{CONCLUSIONS AND FUTURE WORK}

Given our speculative framing, we were unconcerned with technical implementations of a wedding datagraphy service. Still, the prospect of documenting a wedding with quantified data was entirely plausible, and welcomed by our participants. Through this speculation, we have been able to explore the values and design considerations for materials, tools and services that prioritize documentary uses of quantified data. Just as Rooksby et al. find users sometimes appropriating existing personal trackers in a 'documentary style', we have sought to demonstrate here the case for the explicit design of Documentary Informatics tools. Our exploratory findings and the design opportunities we describe in this paper are first steps, providing impetus and opportunity for future work within the DIS and broader HCI community. We might turn to the rich history of documentary studies as a discipline, to consider how many different modes of documentary may translate, or be represented with, quantified data. A wedding is a very particular event to document, after all. Beyond speculation, we might develop functioning design artifacts or mobile apps, for design-led and empirical studies of Documentary Informatics in the day-to-day. We hope through our own investigation of wedding datagraphy, we have been able to inspire future work in this direction.

\section{ACKNOWLEDGMENTS}

We would like to thank all of the many colleagues and participants who we engaged in this speculative work, but especially our two engaged couples Annabelle \& Calum, and Julia \& Rowan, without whom this work would not have been possible. Thank you also to the thoughtful anonymous reviewers. The second author was supported by The Leverhulme Trust (ECF-2012-642) and the third and fourth authors by the EPSRC (EP/N005848/2). 


\section{REFERENCES}

1. James Auger. 2013. Speculative design: crafting the speculation. Digital Creativity 24, 1: 11-35.

2. Mikhail Bakhtin. 1981. The dialogic imagination: Four essays. University of Texas Press.

3. Richard Banks. 2011. The future of looking back. O’Reilly Media, Inc.

4. Frederic C. Bartlett. 1932. Remembering: An experimental and social study. Cambridge: Cambridge University.

5. Julian Bleecker. 2009. Design Fiction: A short essay on design, science, fact and fiction. Near Future Laboratory 29.

6. Henri Cartier-Bresson. 2014. The Decisive Moment. Simon \& Schuster.

7. Matthew Champion. 2015. Here's what the man with an Xbox controller at St James' Park was actually doing. Retrieved April 4 ${ }^{\text {th }}, 2017$ from https://www.indy100.com/article/heres-what-the-manwith-an-xbox-controller-at-st-james-park-was-actuallydoing--Zk5NjoxLBg

8. Eun Kyoung Choe, Nicole B. Lee, Bongshin Lee, Wanda Pratt, and Julie A. Kientz. 2014. Understanding Quantified-selfers' Practices in Collecting and Exploring Personal Data. In Proceedings of the SIGCHI Conference on Human Factors in Computing Systems (CHI'14), 1143-1152. https://doi.org/10.1145/2556288.2557372

9. Jenny Davis. 2013. The Qualified Self. Retrieved April 4th, 2017 from

http://thesocietypages.org/cyborgology/2013/03/13/the -qualified-self/

10. José van Dijck. 2013. The culture of connectivity: $A$ critical history of social media. Oxford University Press.

11. José van Dijck. 2014. Datafication, dataism and dataveillance: Big Data between scientific paradigm and ideology. Surveillance \& Society 12, 2: 197-208.

12. Judith Donath, Alex Dragulescu, Aaron Zinman, Fernanda Viégas, and Rebecca Xiong. 2010. Data portraits. In ACM SIGGRAPH 2010 Art Gallery, 375383. http://dx.doi.org/10.1145/1836786.1836793

13. Anthony Dunne and Fiona Raby. 2013. Speculative everything: design, fiction, and social dreaming. MIT Press.

14. Chris Elsden, David Chatting, Abigail C. Durrant, Andrew Garbett, Bettina Nissen, John Vines, and David S. Kirk. 2017. On Speculative Enactments. In Proceedings of the 2017 CHI Conference on Human Factors in Computing Systems (CHI '17),
Forthcoming.

http://dx.doi.org/10.1145/3025453.3025503

15. Chris Elsden, Abigail C. Durrant, David Chatting, David Green, and David S. Kirk. 2017. Abacus Datagraphy: A Speculative Enactment. In 3rd Biennial Research Through Design Conference. 2017. https://figshare.com/articles/Abacus_Datagraphy_A_S peculative_Enactment/4746961

16. Chris Elsden, Abigail C. Durrant, and David S. Kirk. 2016. It's Just My History Isn't It?: Understanding Smart Journaling Practices. In Proceedings of the 2016 CHI Conference on Human Factors in Computing Systems (CHI'16), 2819-2831. https://doi.org/10.1145/2858036.2858103

17. Chris Elsden, David S. Kirk, Abigail C. Durrant. 2016. A quantified past: Toward design for remembering with personal informatics. Human-Computer Interaction, 31(6), 518-557. https://doi.org/10.1080/07370024.2015.1093422

18. Chris Elsden, Bettina Nissen, Andrew Garbett, David Chatting, David S. Kirk, and John Vines. 2016. Metadating: Exploring the Romance and Future of Personal Data. In Proceedings of the 2016 CHI Conference on Human Factors in Computing Systems (CHI '16), 685-698. https://doi.org/10.1145/2858036.2858173

19. Chris Elsden, Mark Selby, Abigail C. Durrant, and David S. Kirk. 2016. Fitter, happier, more productive: what to ask of a data-driven life. interactions 23, 5: 45-45. https://doi.org/10.1145/2975388

20. Daniel A. Epstein, Bradley H. Jacobson, Elizabeth Bales, David W. McDonald, and Sean A. Munson. 2015. From "Nobody Cares" to "Way to Go!": A Design Framework for Social Sharing in Personal Informatics. In Proceedings of the 18th ACM Conference on Computer Supported Cooperative Work \& Social Computing (CSCW'15), 1622-1636. https://doi.org/10.1145/2675133.2675135

21. Daniel A. Epstein, An Ping, James Fogarty, and Sean A. Munson. 2015. A Lived Informatics Model of Personal Informatics. In Proceedings of the 2015 ACM International Joint Conference on Pervasive and Ubiquitous Computing (UbiComp '15), 731-742. https://doi.org/10.1145/2750858.2804250

22. Nicholas Felton. 2014. Reporter App. Retrieved April $4^{\text {th }}, 2017$ from http://www.reporter-app.com/

23. Nicholas Felton. 2016. Photoviz. Gestalten.

24. Nicholas Felton. 2014. 2014 Feltron Annual Report. Retrieved April 4 ${ }^{\text {th }}, 2017$ from http://feltron.com/FAR14.html

25. Christopher Frayling. 1993. Research in art and design. 
26. Bill Gaver, Tony Dunne, and Elena Pacenti. 1999. Design: cultural probes. interactions 6, 1: 21-29. https://dx.doi.org/10.1145/291224.291235

27. William Gaver. 2011. Making Spaces: How Design Workbooks Work. In Proceedings of the SIGCHI Conference on Human Factors in Computing Systems (CHI '11), 1551-1560. https://doi.org/10.1145/1978942.1979169

28. GoPro. Telemetry and GPS Add New Layers to Your GoPro Story. Retrieved April 4 ${ }^{\text {th }}, 2017$ from https://gopro.com/news/New-Telemetry-Feature-QuikDesktop-App

29. Nanna Gorm and Irina Shklovski. 2016. Sharing Steps in the Workplace: Changing Privacy Concerns Over Time. In Proceedings of the 2016 CHI Conference on Human Factors in Computing Systems (CHI '16), 4315-4319. https://doi.org/10.1145/2858036.2858352

30. Richard Harper, David Randall, Nicola Smyth, Carwyn Evans, Lisa Heledd, and R. Moore. 2008. The past is a different place: they do things differently there. In Proceedings of the 7th ACM conference on Designing interactive systems (DIS '08), 271-280. http://dx.doi.org/10.1145/1394445.1394474

31. IDEO. 2003. Method Cards. Retrieved April $4^{\text {th }}, 2017$ from https://www.ideo.com/post/method-cards

32. Da-jung Kim, Yeoreum Lee, Saeyoung Rho, and Youn-kyung Lim. 2016. Design Opportunities in Three Stages of Relationship Development Between Users and Self-Tracking Devices. In Proceedings of the 2016 CHI Conference on Human Factors in Computing Systems (CHI '16), 699-703. https://doi.org/10.1145/2858036.2858148

33. Amanda Lazar, Christian Koehler, Joshua Tanenbaum, and David H. Nguyen. 2015. Why we use and abandon smart devices. In Proceedings of the 2015 ACM International Joint Conference on Pervasive and Ubiquitous Computing, 635-646. http://dx.doi.org/10.1145/2750858.2804288

34. Ian Li, Anind Dey, and Jodi Forlizzi. 2010. A stagebased model of personal informatics systems. In Proceedings of the SIGCHI Conference on Human Factors in Computing Systems (CHI '10), 557-566. http://dx.doi.org/10.1145/1753326.1753409

35. Michael Massimi, Richard Harper, and Abigail J. Sellen. 2014. "Real, but Glossy": Technology and the Practical Pursuit of Magic in Modern Weddings. In Proceedings of the 17th ACM Conference on Computer Supported Cooperative Work \& Social Computing (CSCW'14), 854-865. https://doi.org/10.1145/2531602.2531682
36. David Middleton and Steven D. Brown. 2005. The social psychology of experience: Studies in remembering and forgetting. Sage.

37. Andrew D. Miller and W. Keith Edwards. 2007. Give and take: a study of consumer photo-sharing culture and practice. In Proceedings of the SIGCHI Conference on Human Factors in Computing Systems (CHI' 07), 347-356. http://dx.doi.org/10.1145/1240624.1240682

38. Dawn Nafus. 2016. Quantified: Biosensing technologies in everyday life. MIT Press.

39. William Odom, Richard Banks, David Kirk, Richard Harper, Siân Lindley, and Abigail Sellen. 2012. Technology heirlooms?: considerations for passing down and inheriting digital materials. In Proceedings of the SIGCHI Conference on Human Factors in Computing Systems (CHI' 12), 337-346. http://dx.doi.org/10.1145/2207676.2207723

40. William Odom, John Zimmerman, and Jodi Forlizzi. 2014. Placelessness, spacelessness, and formlessness: experiential qualities of virtual possessions. In Proceedings of the 2014 conference on Designing interactive systems (DIS '14), 985-994. http://dx.doi.org/10.1145/2598510.2598577

41. Mimi Onohua. 2015. Pathways. Retrieved April $4^{\text {th }}$, 2017, from http://www.nationalgeographic.com/pathways/

42. Stefanie Posavec and Giorgia Lupi. 2016. Dear Data. Penguin.

43. Jill Walker Rettberg. 2014. Seeing ourselves through technology: How we use selfies, blogs and wearable devices to see and shape ourselves. Palgrave Macmillan.

44. Sean Rintel, Richard Harper, and Kenton O'Hara. 2016. The Tyranny of the Everyday in Mobile Video Messaging. In Proceedings of the $2016 \mathrm{CHI}$ Conference on Human Factors in Computing Systems, (CHI '16), 4781-4792. https://doi.org/10.1145/2858036.2858042

45. John Rooksby, Mattias Rost, Alistair Morrison, and Matthew Chalmers Chalmers. 2014. Personal Tracking As Lived Informatics. In Proceedings of the 32nd Annual ACM Conference on Human Factors in Computing Systems (CHI '14), 1163-1172. https://doi.org/10.1145/2556288.2557039

46. Tony Salvador, Genevieve Bell, and Ken Anderson. 1999. Design ethnography. Design Management Journal (Former Series) 10, 4: 35-41.

47. Risto Sarvas and David M. Frohlich. 2011. From snapshots to social media-the changing picture of 
domestic photography. Springer Science \& Business Media.

48. Donald A. Schön. 1983. The reflective practitioner: How professionals think in action. Basic books.

49. Tamar Sharon. 2016. Self-Tracking for Health and the Quantified Self: Re-Articulating Autonomy, Solidarity, and Authenticity in an Age of Personalized Healthcare. Philosophy \& Technology: 1-29. https://doi.org/10.1007/s13347-016-0215-5

50. Alex S. Taylor, Siân Lindley, Tim Regan, David Sweeney, Vasillis Vlachokyriakos, Lillie Grainger, and Jessica Lingel. 2015. Data-in-Place: Thinking through the Relations Between Data and Community. In Proceedings of the 33rd Annual ACM Conference on Human Factors in Computing Systems (CHI' 15), 2863-2872. https://doi.org/10.1145/2702123.2702558

51. Nancy Van House and Elizabeth F. Churchill. 2008. Technologies of memory: Key issues and critical perspectives. Memory Studies 1, 3: 295-310.

52. Nancy Van House, Marc Davis, Morgan Ames, Megan Finn, and Vijay Viswanathan. 2005. The uses of personal networked digital imaging: an empirical study of cameraphone photos and sharing. In $\mathrm{CHI} 05$ Extended Abstracts on Human Factors in Computing Systems, 1853-1856. http://dx.doi.org/10.1145/1056808.1057039
53. Peter West, Richard Giordano, Max Van Kleek, and Nigel Shadbolt. 2016. The Quantified Patient in the Doctor's Office: Challenges \& Opportunities. In Proceedings of the 2016 CHI Conference on Human Factors in Computing Systems (CHI '16), 3066-3078. https://doi.org/10.1145/2858036.2858445

54. Kjen Wilkens. 2010. Sensor Poetics. Retrieved April $4^{\text {th }}, 2017$ from http://www.di10.rca.ac.uk/kjenwilkens/

55. Gary Wolf. 2010. The data-driven life. The New York Times 28. Retrieved April $4^{\text {th }}, 2017$ from http://www.nytimes.com/2010/05/02/magazine/02selfmeasurement-t.html

56. Peter Wright and John McCarthy. 2004. Technology as experience. MIT Press.

57. John Zimmerman, Jodi Forlizzi, and Shelley Evenson. 2007. Research through design as a method for interaction design research in HCI. In Proceedings of the SIGCHI Conference on Human Factors in Computing Systems, (CHI' 07), 493-502. http://dx.doi.org/10.1145/1240624.1240704 